\title{
ANÁLISE DE CORROSÃO EM JUNTAS SOLDADAS PELO PROCESSO SMAW NO AÇO API 5L X70 EM MEIO SALINO*
}

\section{Resumo}

\author{
Angel Rafael Arce Chilque ${ }^{1}$ \\ Matheus Jorge de Almeida ${ }^{2}$ \\ Letícia Barbosa Silva ${ }^{2}$ \\ Franciele Vieira de Souza ${ }^{2}$ \\ Filipe Menezes de Freitas $^{2}$ \\ Carla de Araújo Camilo²
}

Este trabalho visa as análises metalograficas qualitativas da região de solda e a análises qualitativas e semi- quantitativa da corrosão em juntas soldadas pelo processo SMAW em tubos do aço API 5L X-70, em solução de $\mathrm{NaCl}$; afim de simular um eventual ambiente de trabalho do aço em questão, conhecer seu comportamento para consequentemente prever e evitar danos corrosivos e diminuição de custos. Para realização do trabalho um tubo de Aço API 5L X70 foi cortado, soldado e dividido em corpos de prova e então imersos em solução de $\mathrm{NaCl}$ nas concentrações de 1,5\% e $4,5 \%$, os corpos de prova foram imersos em soluções estáticas e em agitação. As amostras foram devidamente preparadas de acordo com a norma ASTM G31 para o ensaio de imersão e ficaram imersos por 75 dias. Foi feito o cálculo de perda de massa, taxa de corrosão e micrografias. As amostras apresentaram corrosão do tipo generalizada e por pites, comprovando a teoria de que as amostras com maior concentração e agitadas tiveram uma maior taxa de corrosão, e um maior número de pites. Através das micrografias, foram observadas uma maior concentração de pites na zona termicamente afetada, e também na zona fundida nas amostras que tiveram uma maior concentração de pites. No metal de base houve a presença de pites em menor proporção. No geral pode-se dizer que a junta apresentou uma tolerância à corrosão razoável neste meio.

Palavras-chave: Aço API 5L X70. Metalurgia da Soldagem. Corrosão.

\section{CORROSION ANALYSIS IN WELDS WELDED BY THE SMAW PROCESS IN API 5 L X70 STEEL IN SALINE}

\section{Abstract}

This work aims at the qualitative metallographic analyzes of the weld region and the qualitative and semi-quantitative analyzes of the corrosion in welds welded by the SMAW process in API 5L X-70 steel tubes in $\mathrm{NaCl}$ solution; In order to simulate a possible working environment of the steel in question, to know its behavior in order to anticipate and avoid corrosive damages and cost reduction. To perform the work, a tube of API 5L X70 Steel was cut, welded and divided into test pieces and then immersed in $\mathrm{NaCl}$ solution at concentrations of $1.5 \%$ and $4.5 \%$, the specimens were immersed in static solutions And stirring. The samples were duly prepared according to ASTM G31 for the immersion test and were immersed for 75 days. Mass loss, corrosion rate and micrographs were calculated. The samples showed generalized and pitting corrosion, confirming the theory that the higher concentration and agitated samples had a higher corrosion rate and a higher number of pits. Through the micrographs, a higher concentration of pites was observed in the thermally affected area, and also in the melted zone in the samples that had a higher concentration of pites. In the base metal there was the presence of pites in a smaller proportion. In general it can be said that the joint exhibited a reasonable corrosion tolerance in this medium.

Keywords: Steel API 5L X70. Welding Metallurgy. Corrosion.

1 Eng.Metalúrgico, Docteur es Sciences, Professor da Faenge, UEMG, João Monlevade, MG, Brasil,anarcec@yahoo.com.

2 Graduando(a), Engenharia Metalúrgica, UEMG, João Monlevade, MG, Brasil. 


\section{INTRODUÇÃO}

Atualmente as indústrias energéticas em todo o mundo tem demandado muito o fornecimento de tubos de aço soldados para a exploração de petróleo e condução de seus derivados. Devido a essa crescente demanda pela produção de óleo e gás na sociedade moderna e o esgotamento das reservas de petróleo até então exploradas, levaram à busca e exploração de poços em águas ainda mais profundas, nesses ambientes as condições químicas, físicas e mecânicas são extremamente severas, impondo novos requisitos à seleção de materiais e impulsionando o desenvolvimento de materiais capazes de operarem sob estas condições de forma confiável e durável. [1]

Devido às exigências de mercado, as siderúrgicas se veem instigadas a produzirem aços com alto limite de resistência, boa tenacidade a baixas temperaturas e melhor soldabilidade, com isso os chamados aços ARBL (Alta Resistência e Baixa Liga) foram desenvolvidos a fim de atender às indústrias petrolíferas, estruturais, plataformas offshore, fabricação de tubos e etc. Esses aços apresentam elevado limite de resistência mecânica, boa tenacidade, boa conformabilidade e boa soldabilidade.Com isso surge a era dos aços API $5 \mathrm{~L}$, isso fez com que ao final dos anos 80, o aço API X70 fosse considerado o melhor aço para a construção de dutos, exatamente por possuir boas propriedades mecânicas, facilidade de fabricação e baixos custos. [2]

A ênfase na avaliação da região da solda se dá por ela ser um dos pontos mais suscetíveis a sofrer o processo de corrosão, devido a mudanças microestruturais e tensões concentradas devido ao processo de soldagem [3]. Os dutos soldados, quando em operações são inevitavelmente submetidos a carregamentos dinâmicos produzidos por correntes marinhas e maré, o lado externo da solda fica em contato com a agua do mar rica em cloretos e gases corrosivos. [4]

Sendo assim, industrias petrolíferas tem como um dos seus maiores desafios conhecer e controlar a corrosão em aços utilizados na produção de gasodutos, oleodutos, entre outros, afim de se evitar elevados custos em manutenção de danos causados por corrosão.

Deve-se salientar também que além dos custos que a corrosão ocasiona, esta envolve também questões de segurança, interrupção de comunicações, preservação de monumentos históricos e poluição ambiental como sendo os fatores de maior importância para que se evite a sua ocorrência [4]

Neste estudo, faz um levantamento teórico-experimental, reunindo amplo material bibliográfico sobre o assunto, com a realização de ensaios corrosivos para constatar o efeito das variantes na junta soldada.

O estudo teve como objetivo examinar qualitativamente e quantitativamente a corrosão em juntas soldadas pelo processo SMAW do aço API 5L X70 em meio salino ( $\mathrm{NaCl}$ com agitação e estático) e determinar a sua influência na microestrutura. E para isso foram realizadas sete etapas, sendo elas corte, aplanamento, chanfro em meio $\mathrm{v}$, solda pelo processo SMAW, preparação das amostras (lixamento, polimento), microdureza Vickers, imersão nas soluções salinas, análise macrográfica e micrográfica da corrosão e resultados.

\section{MATERIAIS E MÉTODOS}

A pesquisa utilizou procedimentos experimentais com enfoque quantitativo/qualitativo e levantamento bibliográfico. As atividades de estudos foram 
feitas nos laboratórios de química e metalurgia física e soldagem, e os ensaios de na Universidade do Estado de Minas Gerais, campus João Monlevade, e a metodologia de trabalho é a mesma utilizada por ARCE et al (2012) [5] nos estudo de aços de ARBL e adotada pelo grupo de soldagem da Faenge/UEMG.

\subsection{Metal de Base}

O aço API 5L X70 é o metal de base utilizado para o desenvolvimento deste trabalho e é especificado pela norma API 5L (2000) [6]. A tabela 1 descreve a composição química do material em estudo e a figura 2, mostra o tubo em seu estado inicial.

Tabela 1 : Composição Química do Metal de Base.

\begin{tabular}{|c|c|c|c|c|c|c|}
\hline Metal de Base & $\mathbf{C}$ & $\mathbf{S i}$ & $\mathbf{M n}$ & $\mathbf{P}$ & $\mathbf{S}$ & $\mathbf{N}$ \\
\hline \multirow{4}{*}{$\begin{array}{c}\text { API 5L X70 } \\
\text { (tubo, e=3/8") }\end{array}$} & 0,065 & 0,271 & 1,542 & 0,016 & 0,004 & 0,001 \\
\cline { 2 - 7 } & $\mathbf{N i}$ & $\mathbf{C r}$ & $\mathbf{M o}$ & $\mathbf{A l}$ & $\mathbf{V}$ & $\mathbf{N b}$ \\
\cline { 2 - 8 } & 0,013 & 0,248 & 0,001 & 0,046 & 0,050 & 0,062 \\
\cline { 2 - 8 } & $\mathbf{T i}$ & $\mathbf{C u}$ & $\mathbf{C a}$ & $\mathbf{V + N b + T i}$ & $\mathbf{C E}$ iiw & $\mathbf{P}_{\mathrm{cm}}$ \\
\cline { 2 - 7 } & 0,014 & 0,008 & 0,002 & 0,126 & 0,391 & 0,171 \\
\hline
\end{tabular}

Fonte: Cortesia ArcelorMittal (2014)

\subsection{Metal de Adição}

Como metal de adição foram utilizados para o processo de solda manual, eletrodo básico com classificação ASW/ASME E9018-M, de 3,25 mm e E7018-1 de 2,5 mm. As composições químicas dos metais de adição podem ser verificadas na Tabela 2 e 3.

Tabela 2 : Composição química do metal de adição AWS/ASME E 9018-M( à esquerda)

Tabela 3 : Composição química do metal de adição ASW/ASME E 7018-1( à direita)

\begin{tabular}{|c|c|c|c|c|c||c|c|c|c|}
\hline Metal de Adição & C & Si & Mn & Ni & Mo & $\begin{array}{c}\text { Metal de } \\
\text { Adição }\end{array}$ & C & Si & Mn \\
\hline E 9018-M 3,25mm & 0,072 & 0,418 & 1,087 & 0,023 & 0,013 \\
\cline { 3 - 8 } & E 70182,5mm & 0,06 & 0,25 & 1,2 \\
\hline
\end{tabular}

Fonte: Catálogo ESAB(2016)

\subsection{Parâmetros de Soldagem}

Tabela 4 - Parâmetros de Soldagem

\begin{tabular}{|c|c|c|c|c|c|c|}
\hline Processo & Cordão & $\begin{array}{c}\text { Corrente } \\
(\mathbf{A})\end{array}$ & $\begin{array}{c}\text { Tensão } \\
\mathbf{( V )}\end{array}$ & $\begin{array}{c}\text { Velocidade } \\
(\mathbf{m m} / \mathbf{s})\end{array}$ & $\begin{array}{c}\text { Aporte } \\
\text { Térmico } \\
(\mathbf{J} / \mathbf{m m})\end{array}$ & $\boldsymbol{\eta}$ \\
\hline SMAW & RAIZ & 110 & 24 & 1,23 & 1695 & 0,79 \\
\hline SMAW & ECHIMENTO & 110 & 24 & 1,18 & 1767 & 0,79 \\
\hline SMAW & $1^{\circ}$ ACABAMENTO & 130 & 24 & 1,12 & 2200 & 0,79 \\
\hline SMAW & $2^{\circ}$ ACABAMENTO & 130 & 24 & 1.08 & 2282 & 0,79 \\
\hline SMAW & $3^{\circ}$ ACABAMENTO & 130 & 24 & 1,21 & 2037 & 0,79 \\
\hline
\end{tabular}

Fonte: Pesquisa Documental (2016) 
Figura 3 - Esquema da junta soldada

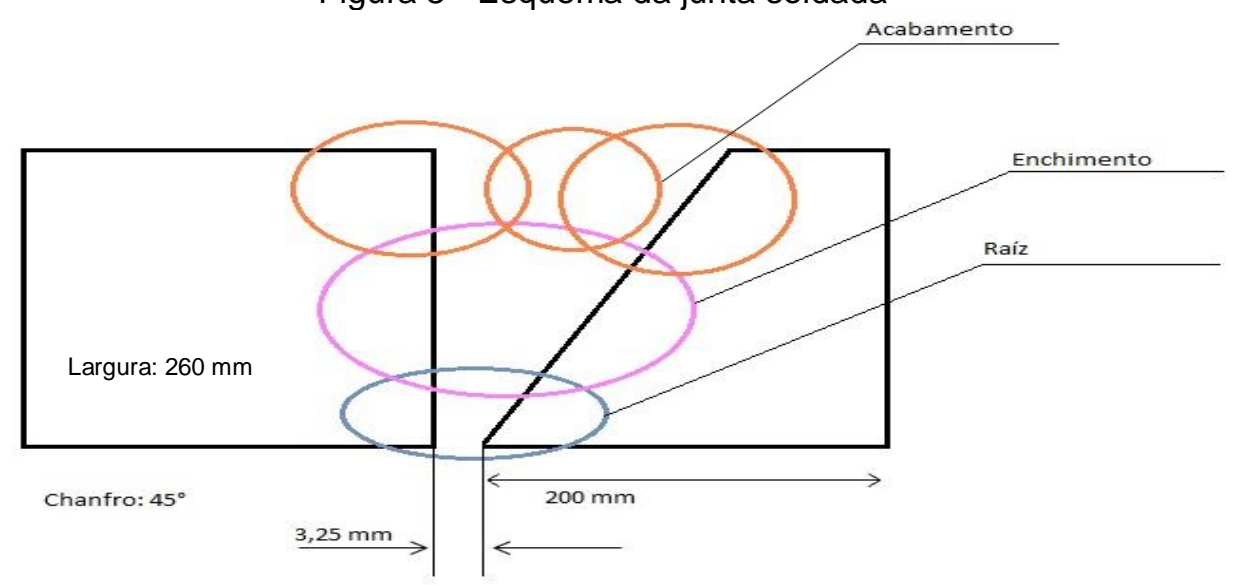

\subsection{Macrografia e Micrografia}

Foram realizadas as análises macrográficas e micrográfica, que consistem na análise de um corpo de prova previamente polido e atacado com Nital $2 \%$ com o objetivo de expor a macroestrutura e a microsestrutura da peça em análise.

\subsection{Ensaio de Microdureza}

O ensaio de Microdureza Vickers foi realizado utilizando o microdurômetro SHIMADZU®, modelo HMV - 2T seguido a norma ASTM E384.

\subsection{Ensaio de Imersão}

O ensaios de corrosão foi baseado na Norma ASTM G 31 para ensaio de imersão total. As amostras foram então submetidas às soluções de cloreto de sódio por 75 dias para avaliar o efeito corrosivo das mesmas.

Figura 6: Dimensões das amostras imersas

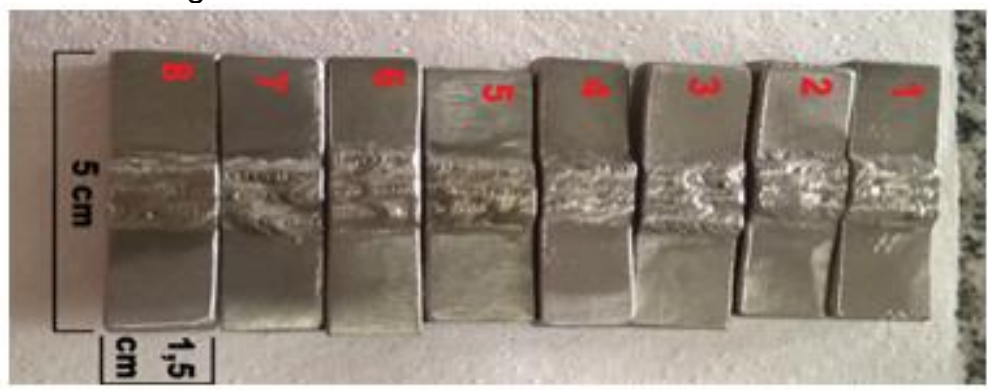

Fonte: Pesquisa Documental (2017)

\section{Resultados e discussões}

\subsection{Macrografia}

Através da macrografia é possível observar a orientação dos cordões de solda. Representados pelos números : 1: Cordão de Raiz; 2: Cordão de Enchimento; 3,4,5: Cordões de Acabamento. A junta soldada está livre de defeitos e descontinuidades. 
Figura 8: Macrografia dos cordões de solda

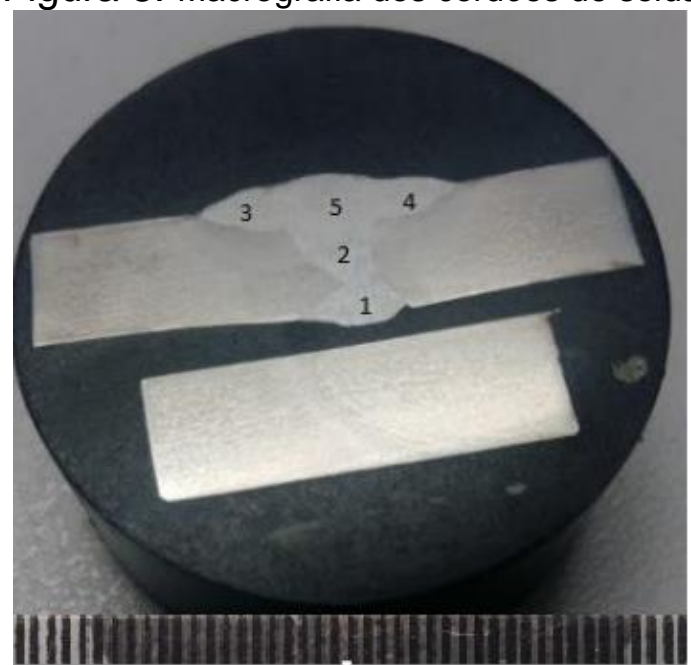

Fonte: Pesquisa Documental (2017)

\subsection{Microdureza}

A seguir estão representados os perfis de microdureza obtidos nos corpos de prova da junta soldada. O lado de referência é o esquerdo da amostra.

Figura 11 : Perfis de Microdureza

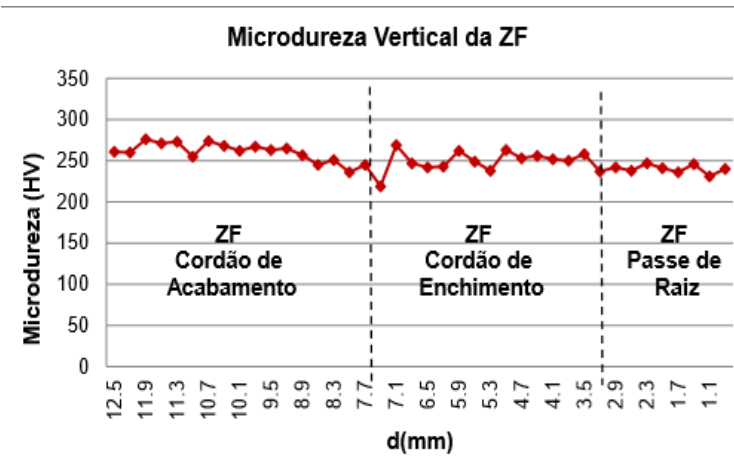

Microdureza Horizontal da ZF - $4^{\circ}$ Cordão

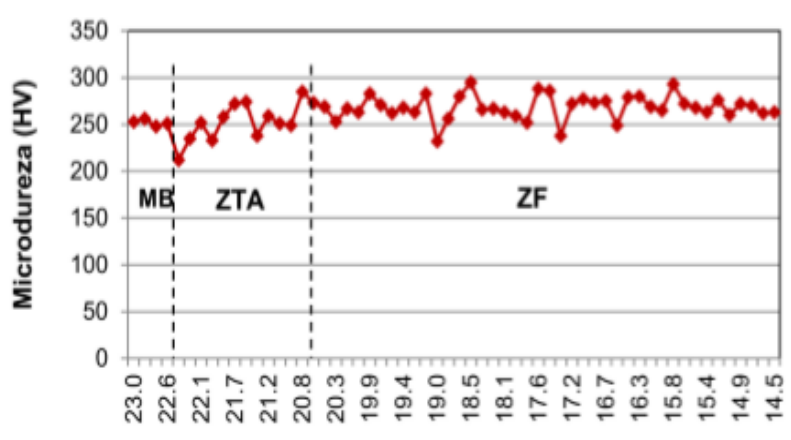

d (mm)
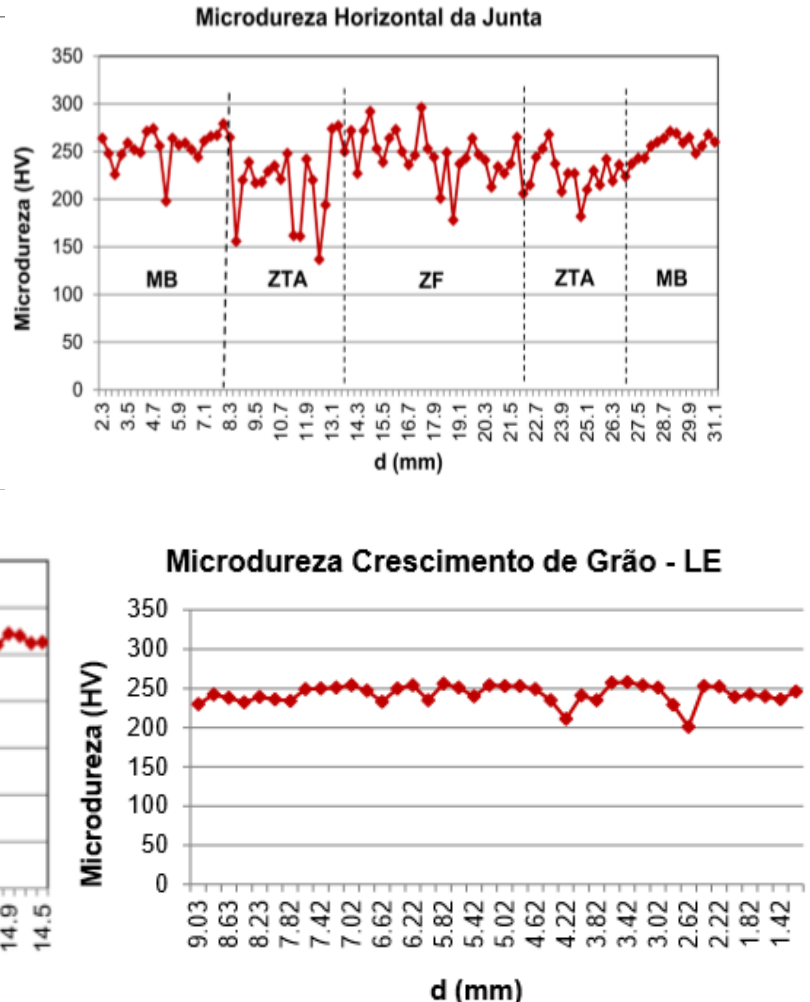

Fonte: Pesquisa Documental ( 2017) 


\subsection{Corrosão}

\subsubsection{Perda de massa}

Tabela 8 - Perda de Massa

\begin{tabular}{|c|c|c|c|c|}
\hline Amostras & \% do Sal & $\begin{array}{c}\text { Massa Inicial } \\
\text { (g) }\end{array}$ & Massa Final (g) & $\begin{array}{c}\text { Perda de Massa } \\
\text { (g) }\end{array}$ \\
\hline 1 & $\begin{array}{c}1,5 \% \text { de } \\
\mathrm{NaCl}\end{array}$ & 52,0487 & 51,534 & 0,5147 \\
\hline 2 & $1,5 \%$ de $\mathrm{NaCl}$ & 47,8732 & 47,4582 & 0,4150 \\
\hline 3 & $\begin{array}{c}1,5 \% \text { de } \\
\mathrm{NaCl} \text { (c/agitação) }\end{array}$ & 49,5234 & 48,8716 & 0,6518 \\
\hline 4 & $\begin{array}{c}1,5 \% \text { de } \mathrm{NaCl} \\
\text { (c/agitação) }\end{array}$ & 55,6445 & 54,9780 & 0,6665 \\
\hline 5 & $\begin{array}{c}4,5 \% \text { de } \\
\mathrm{NaCl}\end{array}$ & 49,5812 & 48,5644 & 1,0168 \\
\hline 6 & $\begin{array}{c}4,5 \% \text { de } \\
\mathrm{NaCl}\end{array}$ & 45,2634 & 44,3855 & 0,8779 \\
\hline 7 & $\begin{array}{c}4,5 \% \text { de } \\
\mathrm{NaCl} \text { (c/agitação) }\end{array}$ & 50,1146 & 49,0834 & 1,0312 \\
\hline 8 & $\begin{array}{c}4,5 \% \text { de } \\
\mathrm{NaCl} \text { (c/agitação) }\end{array}$ & 47,2464 & 46,1044 & 1,1420 \\
\hline
\end{tabular}

Fonte: Pesquisa Documental (2017)

\subsubsection{Taxa de Corrosão Generalizada}

Após a retirada das amostras, foi feito o cálculo da corrosão.

A taxa de corrosão do material é descrita pelo cálculo da perda de milésimos de polegada por ano (mpy). [7]. Os resultados obtidos nestas análises foram calculados conforme fórmula 1.

Formula 1: $\quad m p y=\frac{W K}{A t d}$

$\mathrm{K}=$ constante que vale $534 ; \mathrm{W}=$ perda de massa, expressa em miligramas $(\mathrm{mg})=$ mgi - mgf; $A$ = área do corpo de prova exposta (in 2 ); $d=$ densidade $\quad=7,85 \mathrm{~g} / \mathrm{cm}^{3}$; $\mathrm{t}=$ tempo de exposição (horas).

Tabela 9 - Taxa de corrosão das amostras

\begin{tabular}{|c|}
\hline Amostras \\
\hline 1 \\
\hline 2 \\
\hline 3 \\
\hline 4 \\
\hline 5 \\
\hline 6 \\
\hline 7 \\
\hline 8 \\
\hline
\end{tabular}

Taxa de Corrosão (mpy/ano)
4,53
3,71
5,58
5,60
9,25
7,73
9,12
10,22

Fonte: Pesquisa Documental (2017) 
Gráfico 1: Taxa de corrosão de cada amostra

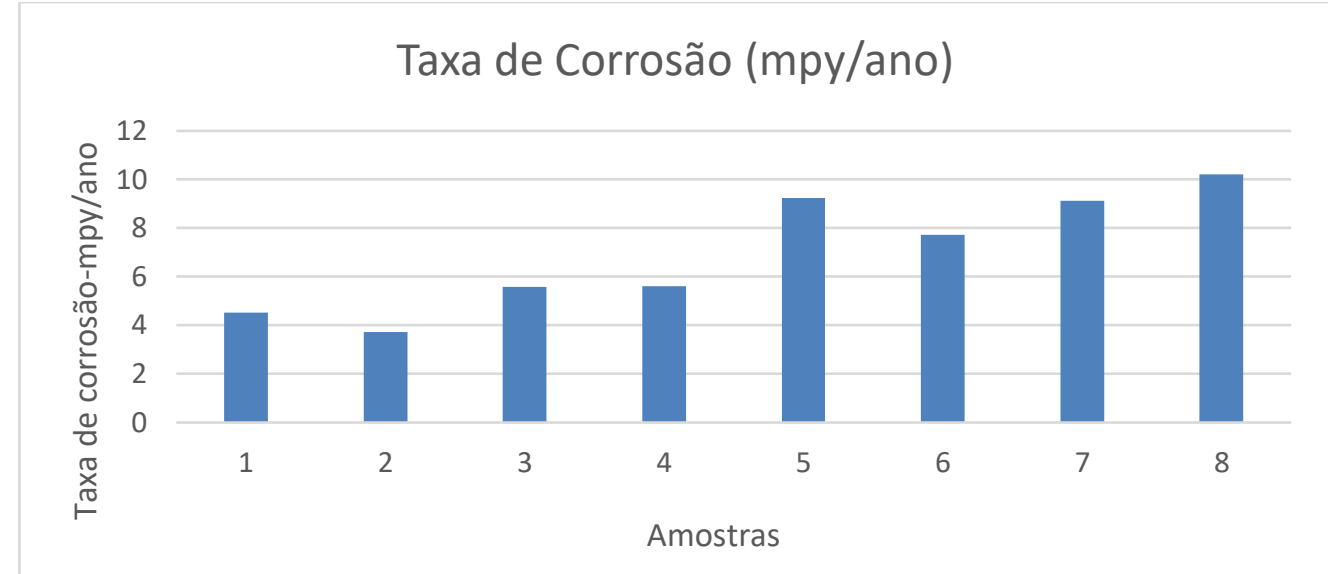

Fonte: Pesquisa Documental

A partir dos resultados obtidos para cada amostra, classifica os metais em 3 grupos quanto a sua taxa de corrosão. [7]

Portanto, pode-se notar que a maioria das amostras imersas apresentaram taxa de corrosão acima de 5 mpy, então conclui que todas apresentam tolerância à corrosão neste meio. Entretanto, as amostras imersas em solução contendo 1,5\% de $\mathrm{NaCl}$ sem agitação, apresentaram taxa inferior a $5 \mathrm{mpy}$, sendo então classificadas como boa resistência a corrosão a esse meio. [7]

\subsubsection{Taxa de Corrosão Localizada}

Quando se trata de corrosão por pites,a perda de massa é em geral insignificante e não ajuda a dar ideia suficiente da gravidade do processo.

Sendo assim, procura-se determinar: o número de pites por unidade de área; o tamanho médio dos pites; a profundidade máxima e a profundidade média dos mesmos .[8]

\subsubsection{Micrografia}

Nesse tópico será mostrada as análises micrográficas de cada amostra após retiradas da solução.

I. Amostras Imersas em Solução $\mathrm{NaCl}$ - sem agitação 1,5 \% :

Figura 14: Metal de Base, aumento 200x:

Figura 15: Linha de Fusão, 200x
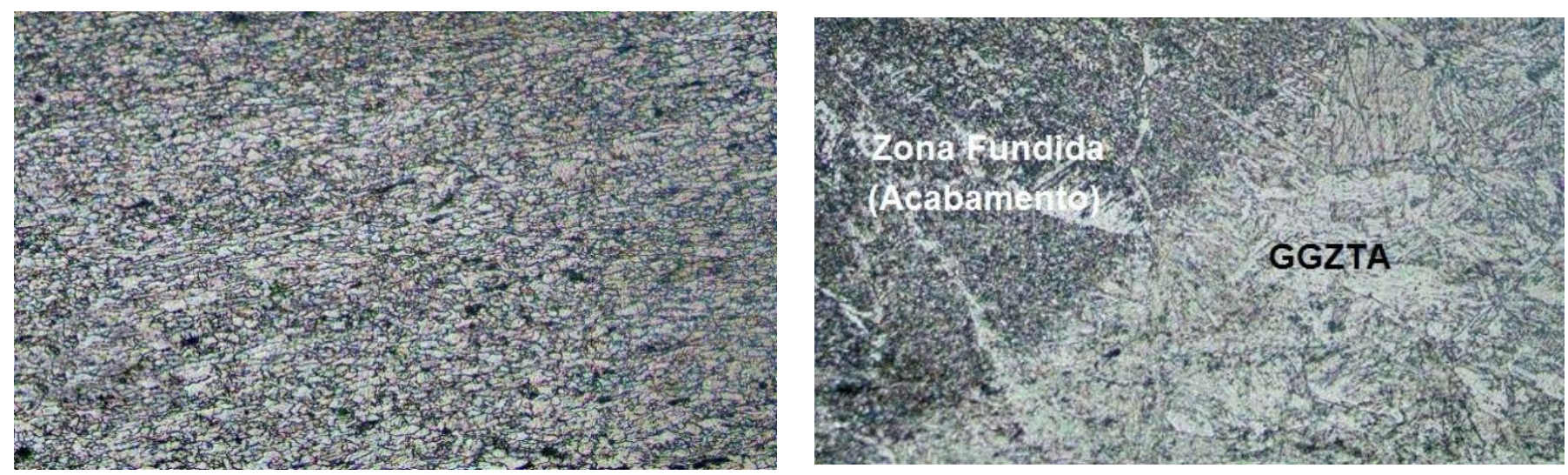
Figura 16 : Região da Zona Afetada pelo Calor-Região de Grãos Finos, 200x.( à esquerda) Figura 17: Região da Zona Fundida- Cordão de Acabamento, 200x. ( à direita)

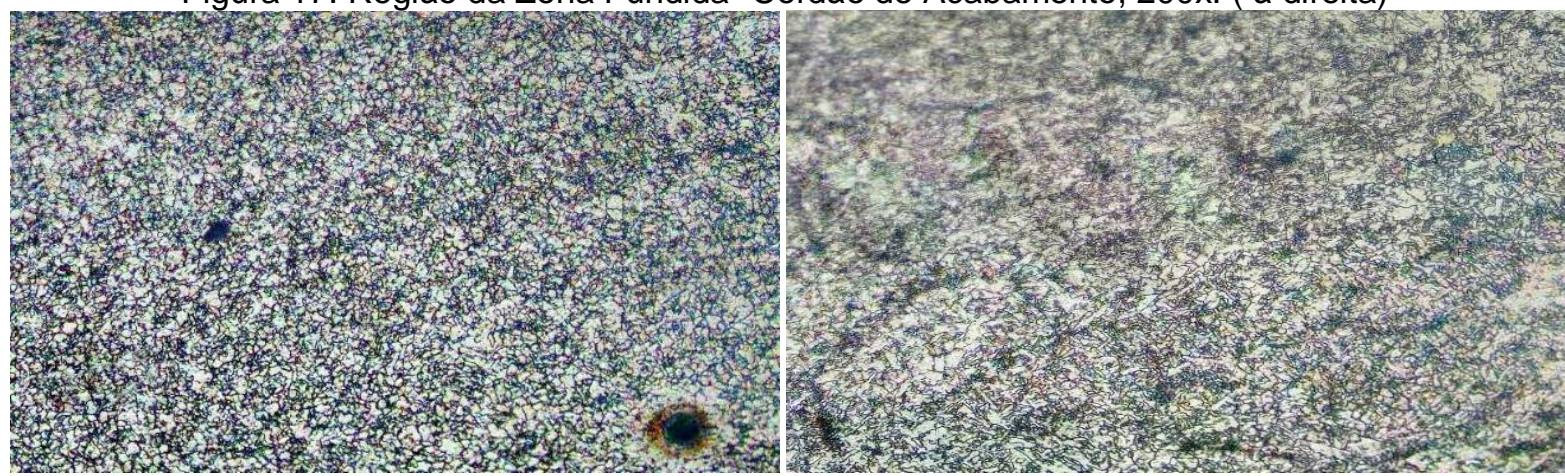

Fonte: Pesquisa Documental (2017)

Como se pode observar através das micrografias, a corrosão por pites nestas amostras se deu em menor número em comparação com as outras amostras.

\section{Amostras Imersas em Solução $\mathrm{NaCl} 4,5 \%$ - sem agitação :}

Figura 18: Linha de Fusão , 200x

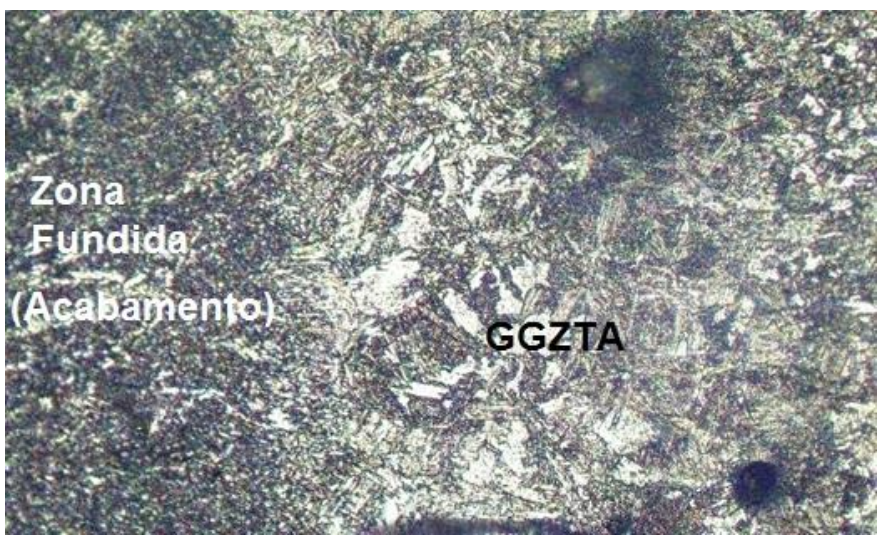

Figura 19: Cordão de Enchimento (Zona Fundida), 100x

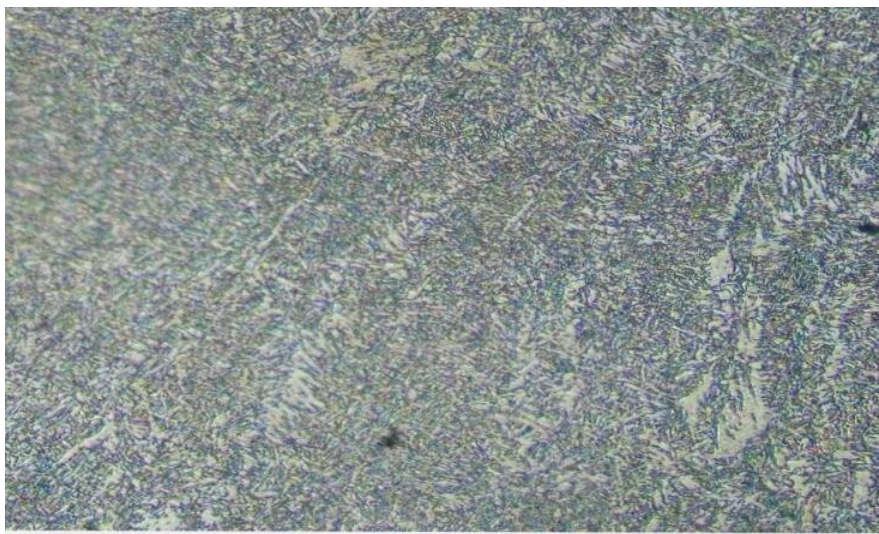

Figura 20 : Região da Zona Afetada pelo Calor- Região de Grãos Finos, 100x

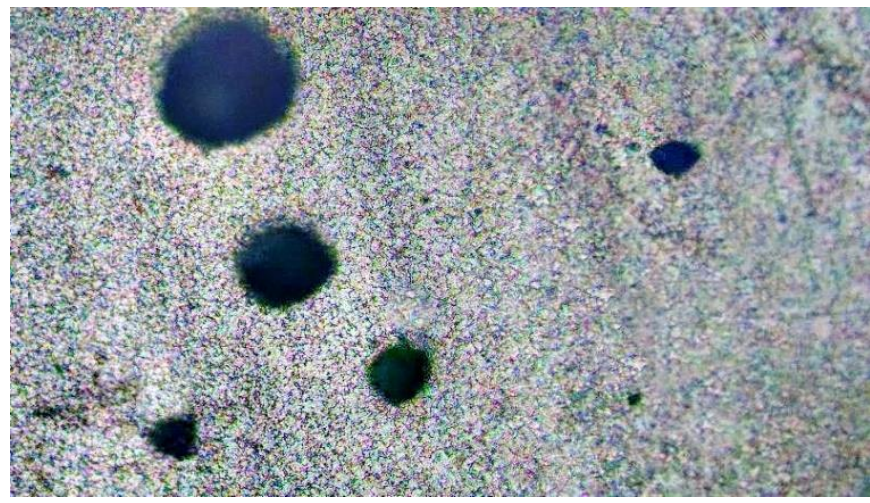

Fonte: Pesquisa Documental (2017)

A maior concentração do $\mathrm{NaCl}$ fez com que aumentasse o número de pites em relação as amostras imersas em menor concentração..

III. Amostras Imersas em Solução $\mathrm{NaCl} 1,5 \%$ - com agitação : 
Figura 21: Linha de Fusão , 200x

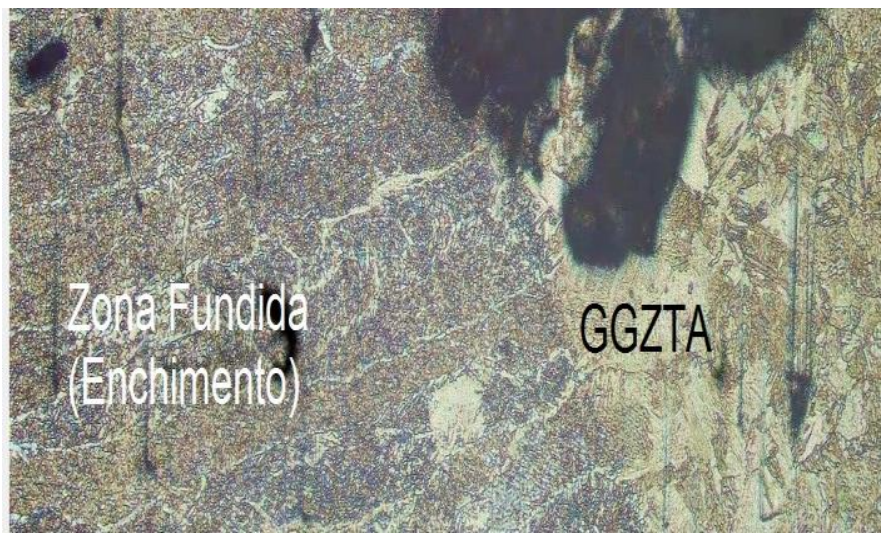

Figura 22: Zona Afetada pelo Calor Região de Grãos Finos, 100x

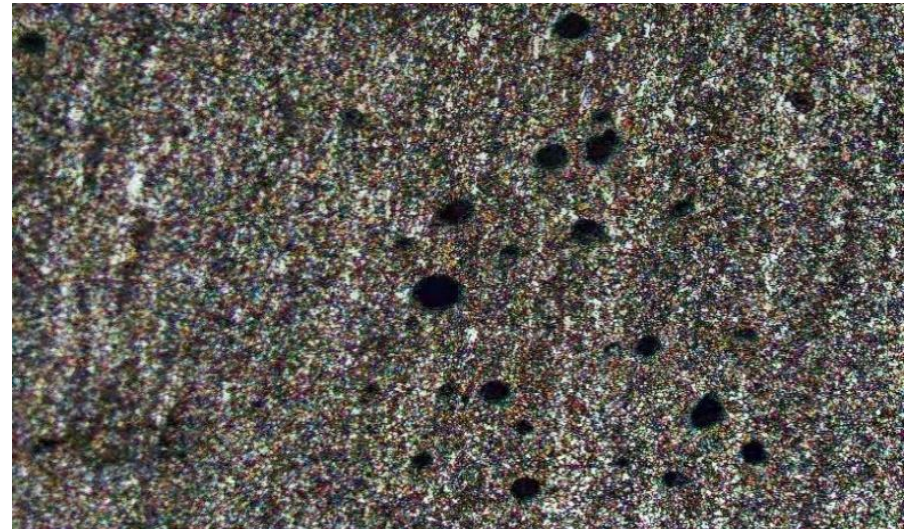

Figura 23: Região da Zona Fundida- Cordão de Enchimento, 100x

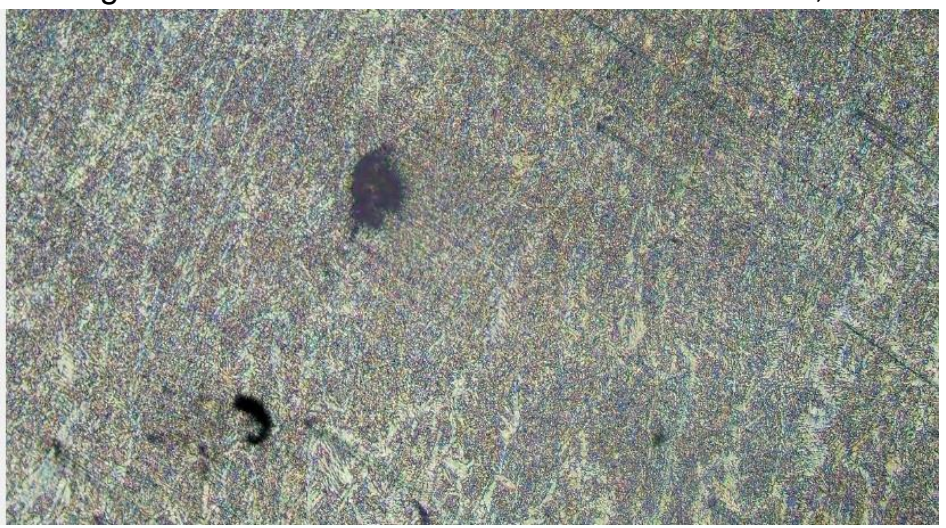

Fonte: Pesquisa Documental (2017)

Nestas amostras houve uma grande presença de pites, e com tamanhos consideráveis, que se concentraram principalmente na região central.Os pites ocorreram de forma geral na zona afetada pelo calor, principalmente na região de grãos finos.

\section{Amostras Imersas em Solução $\mathrm{NaCl}$ 4,5\% - com agitação :}

Figura 24: Linha de Fusão, 200x

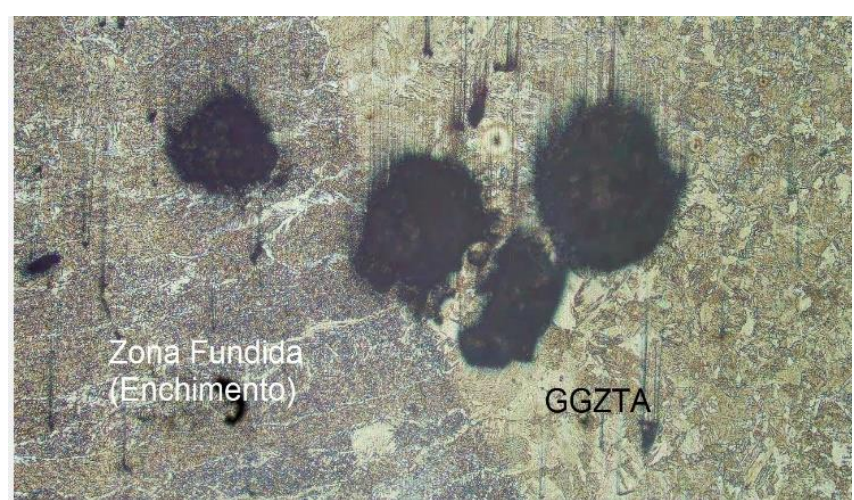

Figura25: Zona Afetada pelo calor- Região de grãos finos, $100 x$

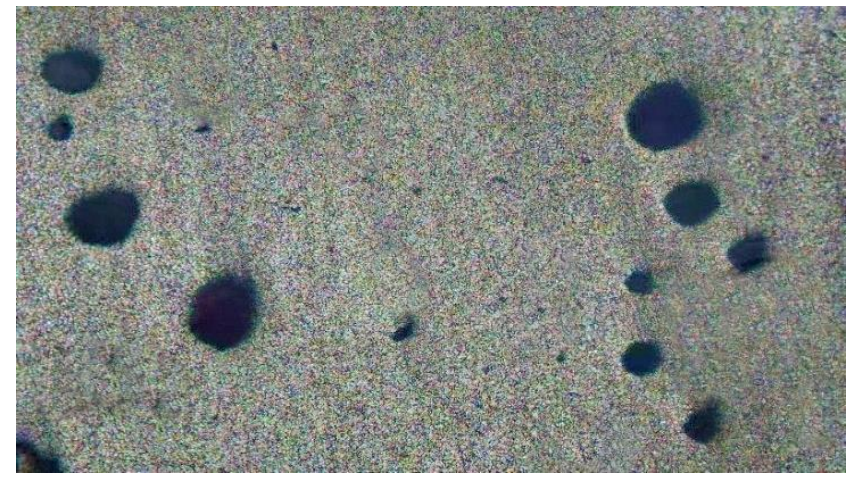


Figura 26:. Região da Zona Fundida- Cordão de Acabamento, 200x

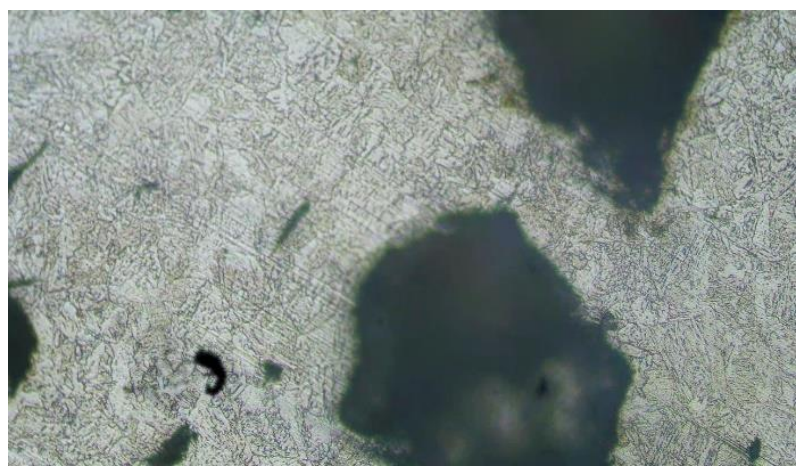

Fonte: Pesquisa Documental (2017)

Estas amostras apresentaram a maior taxa de corrosão generalizada e também apresentaram maior número de pites, portanto foi a amostra que apresentou maior gravidade quanto ao processo corrosivo.

A ocorrência de pites no metal de base foi muito pouca ou inexistente em todas as amostras. O que pode confirmando assim que devido as mudanças microestruturais e tensões concentradas ocasionadas no processo de soldagem, tornam a região de junta soldada região mais sensível ao processo de corrosão localizada.

\section{CONCLUSÕES}

As principais conclusões que os resultados deste estudo experimental possibilitou encontrar foram:

a) O material estudado apresentou corrosão do tipo generalizado e por pites.

b) Como esperado, a região da junta soldada se mostrou mais sensível à corrosão localizada.

c) Confirmando a teoria, a taxa de corrosão foi maior nos materiais expostos às soluções agitadas e com maior concentração do sal.

d) Os pites se formaram principalmente nas amostras cuja solução foram agitadas, localizando-se na zona fundida e principalmente na região de zona afetada pelo calor.

e) O material em geral apresentou tolerância à corrosão neste meio. As soluções com menor concentração do sal e que não foram agitadas tiveram uma boa resistência a corrosão.

\section{Agradecimentos}

Os autores gostariam de expressar seu agradecimento ao Laboratório de Transformação da Faenge, a Esab pelo fornecimento de consumíveis, ao CETEN pelo apoio logístico, a FAPEMIG pelo apoio finnancei e aos graduandos de Engenharia metalúrgica do grupo de soldagem da FaEnge/UEMG do pelo apoio dado na execução deste trabalho.

\section{REFERÊNCIAS BIBLIOGRÁFICAS}

[1] RITA DE SOUZA, C.; ANTÔNIO MARTINS, W. Caracterização Metalográfica e Mecânica de Tubo de Aço API 5L X70 Soldado com Multipasses Pelo Processo SMAW em Condições Específicas de Energía de Soldagem. Graduados-[s.I.] Universidade do Estado de Minas Gerais - Faculdade de Engenharia, 2014. 
[2] FRAUCHES-SANTOS, Cristiane et al. The Corrosion and the Anticorrosion Agents. Revista Virtual de Química, [s.I.], v. 6, n. 2, p.296-298, 2014. GN1 Genesis Network. DOI: 10.5935/19846835.20140021.

[3] MODENESI, P. J.; MARQUES P. V.; DAGOBERTO B. S. Introdução à metalurgia da soldagem. Belo Horizonte: Ed UFMG, 2012.

[4] GENTIL, V., Corrosão, Rio de Janeiro: Editora LTC, 2007.

[5] ARCE CH. A.R. et al.Estudo comparativo da micro estrutura e propriedades mecânicas de soldas do aço X80 feitas pelos processos SMAW, TIG (manual) e GMAW/FCAW robotizados. $67^{\circ}$ congresso da ABM. Rio de janeiro, 2012

[6] API 5L 2000. Specification for Line Pipe. API Specification 5L Forth-second edition, january 2000. Washington, D.C, 2000

[7] GENTIL, V. Corrosão. 6. ed. Rio de Janeiro: LTC - Livros Técnicos e Científicos, 2012. 360 p. ISB 9788521618041.

[8] AMERICAN SOCIETY FOR METALS INTERNATIONAL.Metals Handbook,Corrosion, Vol 13, 9ed.1987 